\title{
Efficacy and Safety of Using N-Butyl Cyanoacrylate in Cranial Fixation Following Trauma and Other Pathologies
}

\author{
Ahmed SULTAN, Abbas MOHAMED \\ Alexandria University, Department of Neurosurgery, Alexandria, Egypt
}

\section{ABSTRACT}

AIM: Skull bone fixation following different cranial surgeries is essential and should be rigid, simple and cheap. We describe our technique of cranial fixation using the adhesive cyanoacrylates.

MATERIAL and METHODS: At the end of cranial and intracranial surgeries the craniotomy flap and bone pieces are returned, realigned and fixed using Histoacryl $(\mathrm{N}$-Butyl Cyanoacrylate) glue. The glue is applied all around the flap in 360-degree fashion.

RESULTS: The adhesive material was used in 24 cases after different surgeries involving the calvaria of the skull. Patient age ranged from 1 month to 55 years. Seven cases presented with depressed fractures, 5 traumatic hematomas, and 2 cases after decompressive craniotomies for malignant middle cerebral artery (MCA) infarctions, and 10 cases operated for brain tumors. No skin or bone flap infections were encountered during the follow up period and fusion of the edges of bone flap was observed on follow-up imaging in most of the cases.

CONCLUSION: Skull bone realignment and fixation using glue is a simple, safe, and inexpensive method. The operative procedure was not prolonged. Good cosmetic appearance and realignment and fusion of the bone flap were achieved. Further neuroimaging methods are not prohibited. Glue is suitable for the growing skull of children. Glue is also suitable in compound depressed fractures of the skull with possibility of infection.

KEYWORDS: Cranium, Cyanoacrylate, Efficacy, Fixation, Fracture

\section{INTRODUCTION}

$\mathrm{R}$ ealignment and fixation of skull bones following intracranial surgeries or skull fractures is an important issue for all neurosurgeons and patients (4). At the end of cranial and intracranial surgeries, the tired neurosurgeon needs a simple and rapid method of skull bone reconstruction. Different techniques are available for bone flap fixation. The optimum method should allow rapid solid fixation without any morbidity. The operative procedure should not be prolonged.

In this study, we will assess the use of cyanoacrylate glue for fixation of skull bone following intracranial surgeries $(2,4,6,8,12)$.

\section{MATERIAL and METHODS}

At the end of cranial and intracranial surgeries, the craniotomy flap and bone pieces are returned, realigned and fixed using Histoacryl (N-Butyl Cyanoacrylate) glue. The glue is applied all around the flap in 360-degree fashion.

\section{RESULTS}

The adhesive material was used in 24 cases after different surgeries involving the calvaria of the skull (Table I). Seven cases were presented with traumatic depressed fractures, the bone fragments were applied to the defects and glue was applied to whole edges of the fragments. Five patients had traumatic extradural hematomas, one patients after 
Table I: The Distribution of the Patients according to the Diagnosis and Approach

\begin{tabular}{|c|c|c|c|c|c|c|}
\hline $\begin{array}{l}\text { Patient } \\
\text { No }\end{array}$ & $\begin{array}{c}\text { Age } \\
\text { (years) }\end{array}$ & Sex & Diagnosis & Approach & Morbidity & $\begin{array}{l}\text { Follow-up } \\
\text { (months) }\end{array}$ \\
\hline 1 & 5 & $\mathrm{~F}$ & Frontal depressed fracture & Right frontal & None & 3 \\
\hline 2 & 23 & M & Right parietal depressed frontal & Right parietal & None & 5 \\
\hline 3 & 23 & M & Right parietal depressed & Right parietal & None & 5 \\
\hline 4 & 31 & M & Frontal depressed fracture & Left frontal & None & 6 \\
\hline 5 & 20 & M & Frontal depressed fracture & Right frontal & None & 4 \\
\hline 6 & 43 & M & Frontal depressed fracture & Left frontal & Epilepsy & 3 \\
\hline 7 & 20 & M & $\begin{array}{l}\text { Left temporoparietal depressed } \\
\text { fracture }\end{array}$ & $\begin{array}{l}\text { Left temporoparietal } \\
\text { approach }\end{array}$ & None & 7 \\
\hline 8 & 18 months & $\mathrm{M}$ & Right parietal EDH & Right parietal bone flap & None & 4 \\
\hline 9 & 37 & $\mathrm{M}$ & Right parietal EDH & Frontoparietal flap & None & 6 \\
\hline 10 & 4 & $\mathrm{M}$ & Left temporoparietal EDH & Temporoparietal bone flap & None & 3 \\
\hline 11 & 13 months & $\mathrm{F}$ & Right frontoparietal ASDH & Right frontoparietal bone flap & None & 5 \\
\hline 12 & 16 & M & Left temporoparietal EDH & Temporoparietal bone flap & None & 7 \\
\hline 13 & 3 & $\mathrm{~F}$ & Left frontal tumor apoplexy & Left frontal bone flap & None & 3 \\
\hline 14 & 18 & $\mathrm{M}$ & Left parietal glioma & Frontoparietal flap & None & 5 \\
\hline 15 & 55 & $\mathrm{~F}$ & Left parietal glioma & Left parietal bone flap & None & 5 \\
\hline 16 & 54 & $\mathrm{~F}$ & Left frontal metastasis & Left frontal bone flap & None & 6 \\
\hline 17 & 1 month & $\mathrm{F}$ & Right occipital tumor apoplexy & Right occipital bone flap & None & 6 \\
\hline 18 & 43 & $\mathrm{M}$ & Left temporal glioma & Right temporal bone flap & Tumor recurrence & 24 \\
\hline 19 & 40 & $\mathrm{~F}$ & Left frontal glioma & Left frontal glioma & Tumor recurrence & 20 \\
\hline 20 & 65 & M & Olfactory groove meningioma & Bifrontal bone flap & None & 2 \\
\hline 21 & 35 & $\mathrm{~F}$ & Right frontal glioma & Right frontal bone flap & Tumor recurrence & 7 \\
\hline 22 & 53 & $\mathrm{~F}$ & Left sphenoid ridge meningioma & Left pterional flap & None & 3 \\
\hline 23 & 65 & $\mathrm{~F}$ & Right malignant MCA infarction & $\begin{array}{l}\text { Right frontotemporoparietal } \\
\text { bone flap }\end{array}$ & $\begin{array}{l}\text { Left sided } \\
\text { hemiplegia }\end{array}$ & 12 \\
\hline 24 & 49 & M & Right malignant MCA infarction & $\begin{array}{l}\text { Right frontotemporoparietal } \\
\text { bone flap }\end{array}$ & $\begin{array}{l}\text { Left sided } \\
\text { hemiplegia }\end{array}$ & 8 \\
\hline
\end{tabular}

M: Male, F: Female, MCA: Middle cerebral artery, EDH: Extradural hematoma, ASDH: Acute subdural hematoma.

evacuation of the frontal extradural developed another parietal epidural hematoma (Figure 1A-E). Two cases had malignant middle cerebral artery (MCA) infarctions. Decompressive craniotomy was done and the bone flap was preserved in the subcutaneous tissue of abdominal wall. Then, after the edema subsided, the bone flap was returned and fixed using the glue. Ten cases were operated for brain tumors and their craniotomy flaps were re-fixed using the glue. Seven cases of the whole series were children younger than 16 years (Figures $2 A-E, 3 A-C)$. No skin or bone flap infections were encountered during the follow up period. Fusion of the edges of bone flap was observed on follow-up imaging in most of the cases.

\section{DISCUSSION}

Following different cranial and intracranial surgeries, the refixation of bone flap is essential to protect the delicate brain and to obtain acceptable cosmetic appearance. The neurosurgeon performing cranial surgery needs a short method of skull fixation at the end of surgery that fulfills the patient wishes. The material used for skull bone reconstruction should be inert, non-irritant and biocompatible (12). The prices of such materials should be low, especially in low income countries. The material should not prevent or obstruct future neuroimaging of the patient and the artifacts should be minimized. Fixa- 

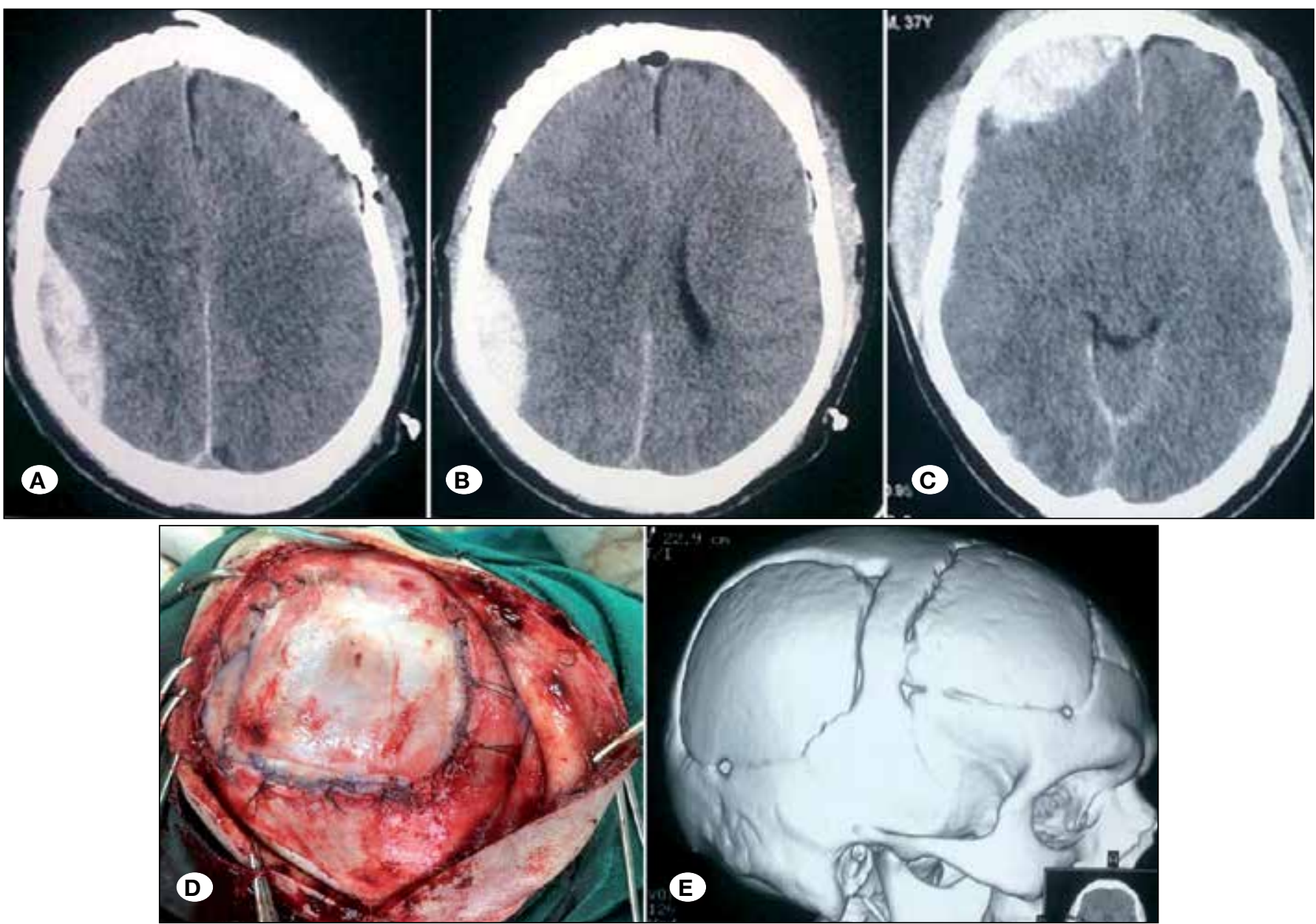

Figure 1: A 37-year-old male had a road traffic accident. After transfer to the emergency department, the Glasgow Coma Scale was 12 and computed tomography (CT) scan showed right frontal extradural hematoma and multiple fissure fractures. Right frontal craniotomy and evacuation of the hematoma were performed. Fixation of the bone flap was done using N-Butyl cyanoacrylate. The patient developed a second parietal extradural hematoma which was then evacuated. The patient was discharged fully conscious and late follow-up CT scan showed a fused flap with good cosmetic appearance.

tion with sutures is inexpensive, but less stable and sinking of the bone flap may occur. Plates, screws, titanium meshes give a rigid realignment, but these materials are expensive and prolong the operative time. Metallic constructs may obstruct further neuroimaging with artifacts. Although these materials are inert, the possibility of infection, foreign body reaction, and rejection are not totally avoidable. Also these plates and meshes may protrude under the scalp leading to a bad cosmetic appearance. Thin scalp may be eroded by metal implants $(2,4,6,8,12)$.

A recent study on the use of artificial custom-made titanium and hydroxyapatite cranioplastic prosthesis has shown a rate of infection of up to $20 \%$ (7).

We found only a few reports in the medical literature about fixation of the bone flap with cyanoacrylate. We described the fixation of bony flaps with this material after the proven efficacy and safety $(5,9,11)$.

Cyanoacrylates are used in many indications of different medical subspecialties. These are used in esophageal varices, cardiac surgery, and embolization of cerebral arteriovenous malformation. They have a proven antibacterial effect especially against gram positive bacteria $(5,9,11)$.

At the end of cranial surgery, the bone flap is repositioned. The glue is applied to the surrounding edge of the flap to ensure solid fixation. In contrast, other materials like sutures or screws are applied to certain points of the flap. We used this technique in 24 patients with different pathologies. Every patient required one or two ampoules of the glue. Many cases showed bone fusion during the clinical and radiological follow up. In cases of depressed fractures, multiple fragments are fused by the polymerized glue. Cyanoacrylates give the bone high degree of stability similar to metallic implants (10). In our cases the bone flap was stable during follow up period and bone fusion was observed in most cases. The cost of

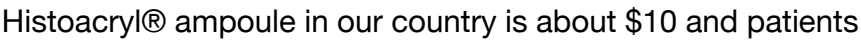
needed 1 or 2 ampoules only, the costs of titanium meshes, mini-plates and screws range from $\$ 150$ to $\$ 500$ which is not suitable for our poor patients. Custom-made implants are more expensive and are not available in Egypt. 

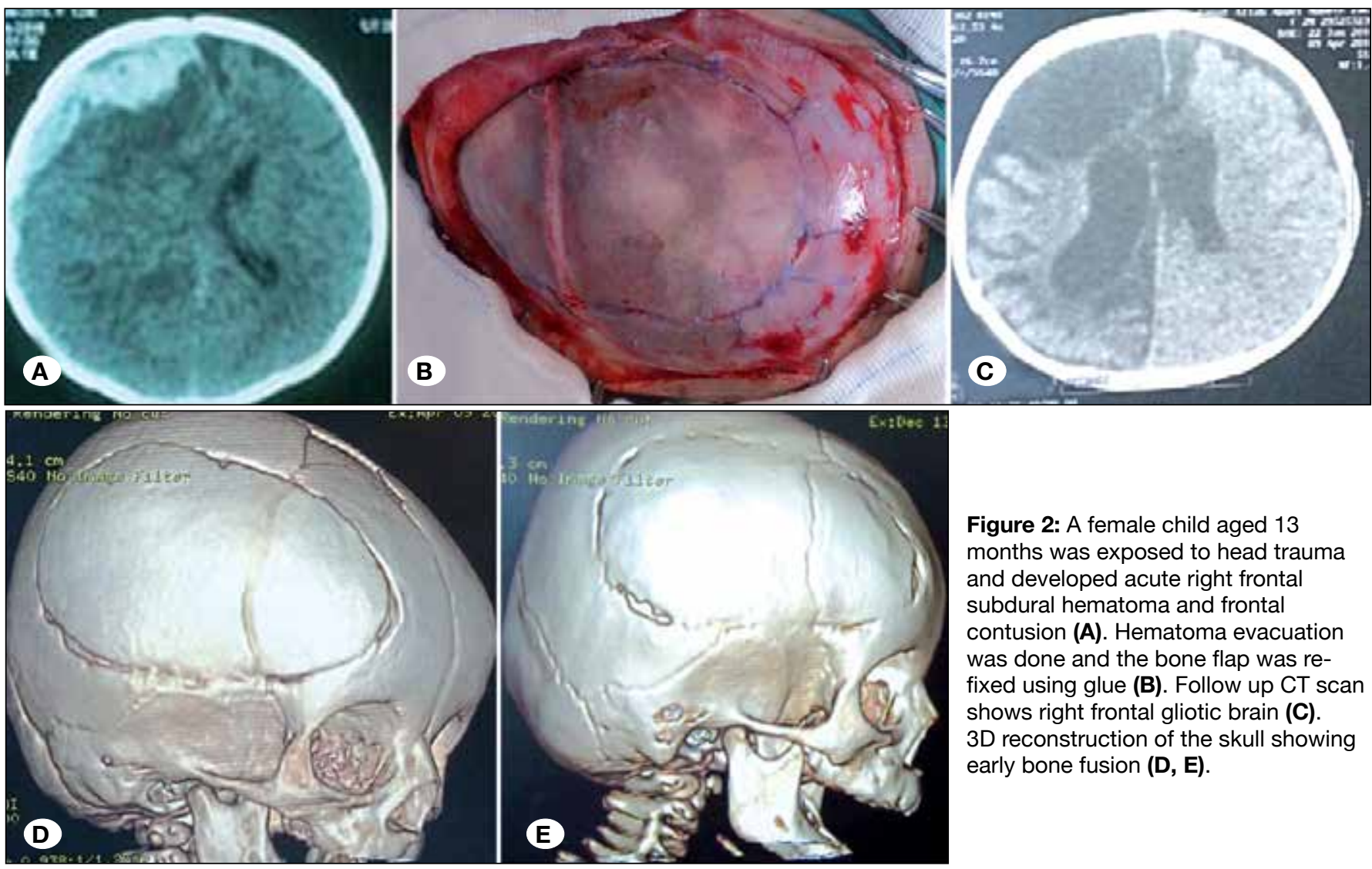

Figure 2: A female child aged 13 months was exposed to head trauma and developed acute right frontal subdural hematoma and frontal contusion (A). Hematoma evacuation was done and the bone flap was refixed using glue (B). Follow up CT scan shows right frontal gliotic brain (C). $3 \mathrm{D}$ reconstruction of the skull showing early bone fusion (D, E).
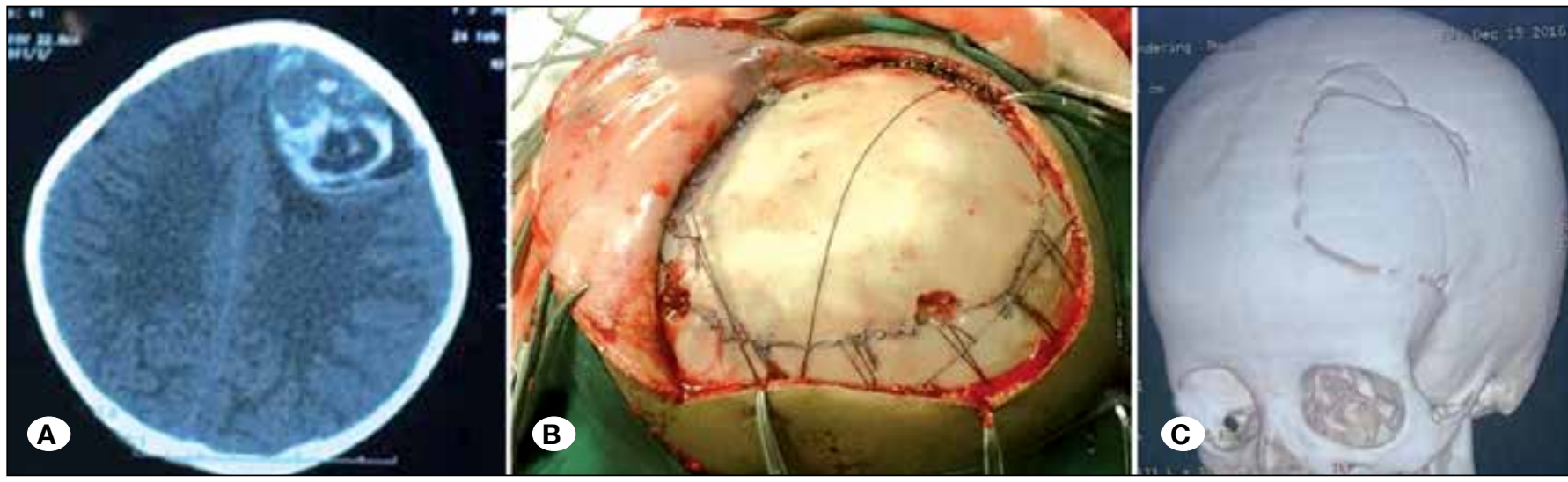

Figure 3: A 3-year-old female child presented with left frontal tumor apoplexy (A). After tumor excision, re-fixation of the bone flap was done using glue (B). Follow up 3D reconstruction of the skull showing fusion of the edges (C).

Gonzalez et al. (5) used ethyl-2-cyanoacrylate for fixation of the cranial bone and experienced the immediate stability and accepted cosmesis with the glue. Foresta et al. (3) found that the use of the glue was helpful in treatment of to treat comminuted fractures of the anterior wall of the maxillary sinus which could not easily be treated with internal rigid fixation. Also Akcal et al. (1) found that cyanoacrylate was rapidly and easily applied in the segmental fractures and it did not adversely affect fracture healing as seen in biopsies during follow-ups.
One of the major advantages is the use in children with growing skull. Rigid metals are not suitable in children and loosen after some time. The use of cyanoacrylate glue guarantee decreased possibility of infection in compound depressed fracture in which metallic implants are contraindicated in the presence of open wounds.

\section{CONCLUSION}

Skull bone realignment and fixation using glue is a simple, safe, and inexpensive method. The operative procedure was 
not prolonged. The cosmetic appearance, realignment and fusion of bone flap were achieved. Further neuroimaging methods are not prohibited. Glue is suitable for the growing skull of children. Glue is suitable in compound depressed fractures of the skull with possibility of infection.

\section{- REFERENCES}

1. Akcal MA, Poyanli O, Unay K, Esenkaya I, Gokcen B, Firatlıgil AS: Effect of $\mathrm{N}$-butyl cyanoacrylate on fracture healing in segmental rat tibia fracture model. J Orthop Surg Res 9:76, 2014

2. Broaddus WC1, Holloway KL, Winters CJ, Bullock MR, Graham RS, Mathern BE, Ward JD, Young HF: Titanium miniplates or stainless steel wire for cranial fixation: A prospective randomized comparison. J Neurosurg 96(2):244247, 2002

3. Foresta E, Torroni A, Gasparini G, Saponaro G, Longo G, Boniello R, Cervelli D, Marianetti TM, Pelo S, Moro A: Use of n-butyl-2-cyanoacrylate (Glubran2(®)) in fractures of orbitalmaxillo-zygomatic complex. J Maxillofac Oral Surg 14(3):761764, 2015

4. Frati A, Pichierri A, Esposito V, Frati R, Delfini R, Cantore G, Bastianello S, Santoro A: Aesthetic issues in neurosurgery: A protocol to improve cosmetic outcome in cranial surgery. Neurosurg Rev 30(1):69-77, 2007

5. Gonzalez E, Orta J, Quero C, Niemshik L, Galera R, Onay D, Rojas O: Ethyl-2-cyanoacrylate fixation of the cranial bone flap after craniotomy. Surg Neurol 53(3):288-289, 2000
6. Lerch KD: Reliability of cranial flap fixation techniques: Comparative experimental evaluation of suturing, titanium miniplates, and a new rivet-like titanium clamp (CranioFix): technical note. Neurosurgery 44:902-905, 1999

7. Lindner D, Schlothofer-Schumann K, Kern BC2, Marx O, Müns A, Meixensberger J: Cranioplasty using custom-made hydroxyapatite versus titanium: A randomized clinical trial. $\mathrm{J}$ Neurosurg 126(1):175-183 2017

8. Noda K, Tanikawa R, Sugimura T, Kawasaki K, Kimura T, Izumi N, Hashimoto M: Use of bioabsorbable plates for cranial fixation. Neurol Med Chir (Tokyo) 49(11):559-562, 2009

9. Romero IL, Malta JB, Silva CB, Mimica LM, Soong KH, Hida RY: Antibacterial properties of cyanoacrylate tissue adhesive: Does the polymerization reaction play a role? Indian $\mathrm{J}$ Ophthalmol 57(5):341-344, 2009

10. Saska S, Hochuli-Vieira E, Minarelli-Gaspar AM, Gabrielli MF, Capela MV, Gabrielli MA: Fixation of autogenous bone grafts with ethyl-cyanoacrylate glue or titanium screws in the calvaria of rabbits. Int J Oral Maxillofac Surg 38(2):180-186, 2009

11. Winston KR, Wang MC: Cranial bone fixation in infants and children. Pediatr Neurosurg 31:225-230, 1999

12. Winston KR, Wang MC: Cranial bone fixation: Review of the literature and description of a new procedure. J Neurosurg 99(3):484-488, 2003 